\title{
Supporting multiple identities in informal spaces: Examining design choice
}

\author{
Brean Prefontaine and Kathleen Hinko \\ Department of Physics and Astronomy, Michigan State University, 220 Trowbridge Rd, East Lansing, MI, 48824

\begin{abstract}
Informal physics programs often have the aim of supporting and cultivating physics identities; however, a student is more than just a physicist. Students have multiple identities, including their racial, cultural, and gender identities, which we believe must be supported within their experiences in informal programs. Informal physics programs that intentionally blend physics learning with other areas of interest (art, music, sports, etc.) are supportive of more than a student's physics identity. In this work, we theorize that blended informal physics programs can be examined using both Critical Race Theory and Critical Physics Identity frameworks to understand how program design possibly supports diverse identities. To demonstrate this hypothesis, we analyze an informal physics practitioner's interview about a youth program involving both art and physics. We look at connections between the theoretical constructs from the two frameworks to understand how informal spaces can be designed to support multiple identities.
\end{abstract}




\section{INTRODUCTION}

Many researchers within the field of physics education research have focused on improvements to classroom environments and the ways that students interact with and learn physics. Over the past decade, some researchers have turned to racial identity as a lens to understand how students perceive the subject, their relationship to it, and the broader physics community. Findings from both racial and physics identity studies have been used to suggest ways to leverage formal classroom learning to increase belonging and potentially create a more inclusive physics culture [1]. The focus on formal environments makes sense from an instructor's perspective and has proven useful in developing transformed (non-lecture based) classrooms [1]. However, informal experiences have been largely overlooked as an integral part of the students' experience with physics. Informal learning environments are differentiated from formal learning spaces by students' degree of agency and voluntary participation, making them potentially powerful experiences for identity [2].

Informal learning can happen in a variety of settings, contexts, and with a variety of participants and facilitators. In this work, we explore how facilitators of informal physics programs can effectively design and plan for engaging a variety of participants from marginalized, oppressed, and underrepresented backgrounds within the K-12 setting. This work is necessary due to ongoing and persisting problems of the physics community lacking both gender and racial diversity despite funding and programming aimed at attracting students to the field [3-5]. Students who feel as though they need to give up their racial and/or gender identities, culture, personal beliefs etc. will not continue within physics [6-9].

One way to counter this idea of needing to give up certain identities in order to "fit in" with physics, is to create informal physics spaces where many identities are celebrated and supported. Third space theory can be used to develop environments where students feel as though they can engage with learning science while not diminishing any important features of the self [10]. Several scholars have taken up the idea there are two distinct spaces within students' lives: the space where students learn science in school and "the second space of the home" [11-13]. Third space theory describes how new forms of participation merge the two main spaces a student experiences to create a third space capable of bringing together different types of knowledge, discourse, relationships, cultures, and identities. We consider third spaces as a way of conceptualizing current and new informal physics programs that allow youth to take up knowledge, resources, and identities in innovative ways that would not be recognized in formal, classroom settings.

In addition to research utilizing this idea of a third space, past research has also shown that spaces revolving around the arts are known to be empowering and supportive of identity expression [14]. However, we recognize that practitioners need to be cognisant about the audience of the program and it is entirely possible that the choice of blended interests can be isolating to certain populations. In this work, we hypothesize that informal physics environments that intentionally blend physics with other interests that are culturally relevant to the participants (such as music, sports, art) may lead to cultivating a physics identity along side other important identities, especially racial and cultural identities. In order to understand how racial identity may or may not be supported in an informal physics setting, we take up two complimentary theoretical frameworks that address different aspects of racial experiences, racial identity, physics experiences, and physics identity: Critical Race Theory (CRT) and Critical Physics Identity (CPI) theory. We use a case study to investigate how each of these frameworks can be used independently to study informal spaces as well as how the intersection of these frameworks can point to aspects of informal physics programs that are important for identity development. An informal summer camp that intentionally blends physics with art has been selected as the context for this paper where we examine an interview with the program facilitator. Within the scope of this paper, we aim to theorize how using Critical Race Theory can be used in conjunction with the Critical Physics Identity framework as an analysis tool for looking at informal physics programs designed to be third spaces.

\section{CRITICAL FRAMEWORKS}

\section{A. Critical Race Theory}

The study of Critical Race Theory (CRT) aims to both understand the social situation of marginalized voices and people of color, and also to encourage scholars to be actively working to transform how society chooses to organize itself into racial hierarchies. CRT started was originated in the legal field during the mid-1970s when many of the civil rights gains from the 1960s were stagnant or being rolled back, and legal studies scholars of color felt the need for new strategies to combat subtle, recurring forms of racism [15]. The ideas contained within CRT quickly spread beyond the field of legal studies and made its way into education research (as early as 1990) where it is currently used to understand and combat racialized experiences within all levels of education [16].

There are many tenets central to CRT, however we are choosing to focus on the following five tenets [15]: racism is ordinary and endemic, interest convergence, race is a social construct, uplifting and centering marginalized voices (counter-storytelling is one method of doing so), and antiessentialism and intersectionality. The top of Table I contains five of the commonly used tenets within CRT and their associated definitions. The Handbook of Research on Science Education explicitly recommends using CRT for studying racial oppression within science education [17]. Furthremore, in physics education research, Rosa and Mensah used CRT to study the educational pathways of black women physicists and assert that "critical race theory can emerge as a potent theoretical framework to discuss race and ethnicity in physics 
education" [16].

\section{B. Critical Physics Identity}

Theorized by Simone Hyater-Adams, et al. the Critical Physics Identity (CPI) framework is a lens to look at the intersection of physics and racial identities $[9,18]$. A framework for science identity was originated by Carlone and Johnson from their study that followed fifteen women of color in various scientific fields [19]. Hazari, et al. took up Carlone and Johnson's science identity framework to create a disciplinespecific physics identity framework that has since been used in many physics education research studies. The CPI framework takes this physics identity framework and combines it with Nasir's framework for racialized identities developed from math education that identifies available (and lacking) resources in different learning environments [20].

Hyater-Adams identified that combining the constructs from these frameworks can "help us show how physics identity differs for physicists across racial or ethnic background" [9]. The six constructs consist of three main ideas from the physics identity framework (recognition, competence/performance, and interest) and three main ideas from the racialized identity framework (relational resources, ideational resources, and material resources). The bottom of Table I shows a summary of these six constructs in the first column and their respective definitions in the second column.

The CPI framework has been used to show the diversity of experiences of Black physicists within the field of physics and the differentiated experiences of Black and white physicists. In a study done by Williams, et al. [21] CPI was used as a tool to understand the experiences of Black physicists who also participate in the performing arts.

\section{Utility of both frameworks}

In this paper, we consider CRT and CPI frameworks both individually and overlapping to examine informal physics programs through the lens of systemic racism and oppression as well as through the physics-specific context. By looking at how systemic forms of oppression affect marginalized voices coupled with understanding the experience of these populations within physics, we will be able to unpack how informal experiences can provide support for marginalized people within physics and the broader society.

\section{METHODOLOGY}

To test the efficacy of using both the CRT and CPI frameworks, we have chosen to look closely at a case study of a informal physics program that includes art content. Data for this case study was collected as part of a larger project to characterize key features of informal physics programs, where de- tailed information about the logistics, activities, and goals of the program, are obtained in semi-structured interviews with lead facilitators of the programs or events. The presented data was obtained in a semi-structured interview with a white, English speaking informal program facilitator (who will be referred to as Taylor) who also identifies with a marginalized population (naming of this population has been left out for anonymity). Taylor is the Director of Outreach and Education at a predominately white institution for physics research and oversees many informal physics programs. Taylor was interviewed virtually by two white, female researchers who work at a university in the midwest.

During the semi-structured interview, Taylor answered questions in the context of a summer camp, referred to as Artistic Physics, designed for elementary and middle school students. The summer camp is a week long program held on the university campus and has 300 students participating over two weeks. The goal of the summer camp is "to provide kids with a positive science experience and to facilitate experiential learning through STEAM activities." We chose Taylor's interview and informal program for analysis due to the physics and arts nature of the curriculum and their selfdescribed "strategic efforts to get a broader variety of people coming to the camp." Taylor's interview was transcribed and coded by one of the white interviewers for all six of the CPI constructs as well as the five tenets of CRT. The data was then presented to classmates for a Critical Race Theory course and written into a graded paper for the same course. Furthermore, the initial paper and results were shared and discussed with the PER faculty and group at her university.

\section{FINDINGS}

We were able to identify instances of every construct from both CRT and CPI within the interview. The third column in Table I contains a summary of coded instances from the interview with Taylor that correspond to the CRT tenet or CPI construct. Each provided example demonstrates the associated construct, but might also have additional constructs present. Taken altogether, these descriptions provide insight as to how the different elements of the Artistic Physics camp are connected to the tension of doing physics activities in the context of a racist society. For example, in this physics learning environment, the endemic nature of racism arose in disciplinary issues stemming from the different backgrounds of campers and counselors. Young campers were confused about race as a social construct when filling out their race on participant surveys that were to document the program demographics to fulfill grant requirements. In Taylor's interview, we also saw instances of systemic racial oppression being recognized within the camp through the use of counter-storytelling by including physics activities that include a variety of cultural elements such as story telling and mythology. Furthermore, the bold examples in Table I highlight aspects of Artistic Physics that aim to connect physics and the arts in order to combat 
TABLE I. Definitions for the CRT tenets (upper part of table) and CPI constructs (lower part of table) and examples from the case study. Bolded examples are those that higlight the arts aspect of Artistic Physics.

\begin{tabular}{|c|c|c|}
\hline Constructs & Framework Definition & Examples from the Interview \\
\hline $\begin{array}{l}\text { Racism is ordinary } \\
\text { and endemic }\end{array}$ & $\begin{array}{l}\text { Racism is permanent and is an added fac- } \\
\text { tor within other forms of oppression }\end{array}$ & $\begin{array}{l}\text { Unexpected discipline issues arose due to diversity such as a camper } \\
\text { threatening "to spray paint his counselor and send him back to Africa" }\end{array}$ \\
\hline $\begin{array}{l}\text { Interest } \\
\text { Convergence }\end{array}$ & $\begin{array}{l}\text { White people will support social justice } \\
\text { only when it serves their own interests }\end{array}$ & $\begin{array}{l}\text { Funding cycles are not ideal for equity research and informal program } \\
\text { design }\end{array}$ \\
\hline $\begin{array}{l}\text { Race is a social } \\
\text { construct }\end{array}$ & $\begin{array}{l}\text { Race is not biological but rather a social } \\
\text { construct }\end{array}$ & $\begin{array}{l}\text { Campers had confusion about demographics/race question on partici- } \\
\text { pant survey because of a lack of understanding about racial categories }\end{array}$ \\
\hline $\begin{array}{l}\text { Counter- } \\
\text { storytelling }\end{array}$ & $\begin{array}{l}\text { Positioning people of color at the center } \\
\text { of the conversation and creating space for } \\
\text { marginalized voices to be heard }\end{array}$ & $\begin{array}{l}\text { Hands-on activities for campers that may not speak English, activities } \\
\text { that include storytelling and different cultural elements, volunteer } \\
\text { physicists who demonstrate a wide range of identities }\end{array}$ \\
\hline $\begin{array}{l}\text { Anti-essentialism and } \\
\text { intersectionality }\end{array}$ & $\begin{array}{l}\text { Not relying on single voices to speak up } \\
\text { for whole groups and analyzing the vari- } \\
\text { ous forms of oppression }\end{array}$ & $\begin{array}{l}\text { Reduced or free camp tuition based upon free or reduced school lunch } \\
\text { status; advertisement for the camp through diverse languages }\end{array}$ \\
\hline Recognition & Being recognized (or not) as a physicist & $\begin{array}{l}\text { Providing positive science experiences; teen counselor program for } \\
\text { previous campers; activities grounded in a diversity of cultures }\end{array}$ \\
\hline $\begin{array}{l}\text { Competence and } \\
\text { Performance }\end{array}$ & $\begin{array}{l}\text { Belief in one's ability to perform and un- } \\
\text { derstand necessary tasks }\end{array}$ & Differing levels of challenge among activities \\
\hline Interest & Interest in the field of physics & $\begin{array}{l}\text { Connecting physics with other interests; relating science to partici- } \\
\text { pants' lives; creative and hands-on activities; enthusiastic facilitators }\end{array}$ \\
\hline Ideational Resource & $\begin{array}{l}\text { Ideas about one's place in physics, what } \\
\text { physicists care about/value, who you are } \\
\text { as a person, and the cultural perceptions } \\
\text { of physicists from outside of the field }\end{array}$ & $\begin{array}{l}\text { Attempting to bring physics out of the academic sphere and into stu- } \\
\text { dents' lives; creating positive science experiences; activities that in- } \\
\text { volve games and crafts; interactive and meaningful activities; same } \\
\text { activities for all age groups; diversity among volunteers }\end{array}$ \\
\hline Relational resource & $\begin{array}{l}\text { The way in which aspects of relation- } \\
\text { ships with others in the context will impact } \\
\text { one's connection to physics }\end{array}$ & $\begin{array}{l}\text { University volunteers, local teachers, and teen counselors; differing } \\
\text { ages of campers interacting through the same activities; counselors } \\
\text { with experience with autism spectrum; diverse counselor identities }\end{array}$ \\
\hline Material resource & $\begin{array}{l}\text { Material things that can provide access to } \\
\text { other identities (ie programs, communi- } \\
\text { ties, organizations, funding) }\end{array}$ & $\begin{array}{l}\text { Low-cost or free tuition for campers in need; pay teachers to create } \\
\text { lesson plans; free transportation for campers in need; advertisement in } \\
\text { many languages; volunteers who are physicists, engineers, and artists }\end{array}$ \\
\hline
\end{tabular}

systemic racism.

The following examples show instances of overlap between the CRT and CPI frameworks within the interview demonstrate how forms of systemic racism and oppression in physics and society can shape an informal physics program.

Youth Recruitment: During the interview, Taylor explained how they inherited the summer camp nine years ago when they started as the Director of Outreach. At that time, the camp was marketed in many ways that did not seem equitable (such as only being advertised to faculty members' for their children), and so Taylor explains some changes that were made:

And so the first year, [...] if you knew about the camp, you got in, and if you didn't, you didn't. [Then] I started sending in flyers to targeted schools, I've made flyers in different languages to send to different community centers. I realized that with our lower income areas, even though they can go to camp for free [...] they still were having travel issues. [...] I actually sent an undergrad in a car to go pick the kids up to bring them to camp for the week. [W]e tried to make it representative of [the local area].

This portion of the interview was coded as both material resource and intersectionality due to the idea that camp fees needed to be lowered in order to create accessibility for lowincome families from all races. This example also shows how Taylor is making an effort to market to families that may not speak English at home and thus increasing accessibility among the community. Taylor later went on to comment: "It was the standard, 'Here's the fee. And if you want financial assistance, you can fill out this application for financial aid.' And I think it's ridiculous that we ask poor people to take more steps." The additional action Taylor took in order to ensure that material resources were available before the start of the camp (with the intention of creating access to participation in the camp) was a way of addressing the tenet of intersectionality by not only targeting specific racial groups but also by recognizing that some racial groups also experience less socioeconomic privileges and may not speak English.

Volunteer Representation: Later in the interview, Taylor comments on the facilitators present during the summer camp and how it is important to have diversity and representation 
among the "experts." Their strategy consisted of:

I always try to have a Black man as a counselor to be a role model for the younger kids. I try to have at least a couple of Latino people as role models for the kids. [...] In terms of the [physics] volunteers, [...] most of my volunteers are not going to be diverse. But of course, that said, in physics women and minorities are more likely to volunteer for things. So you get an unrepresentative group of your students volunteering.

This element of the program provides participants with possible role models that share similar racial identities and recognition that people of color are physicists. The idea of curating volunteers and facilitators that are racially representative of the program participants is in line with the idea that racism is ordinary. We also believe this can be an example of counter-storytelling because Taylor is recognizing that there is a need to provide examples of successful physicists and scientists of color. They focus on an intentional inclusion of people of color in terms of staff members and volunteers, a design choice intended to promote recognition of youth of color through relational resources. However, this act is in tension with their perceived challenge of finding diversity among physics volunteers due the make up of the field.

Physics Activities: In addition to resources available to participants before the start of the program and representation of the facilitators, Taylor also discusses design choices that they made in order to provide support throughout the summer camp. They comment on inclusivity of the spaces and activities used during the camp:

I look at different sites to try to make sure that they're inclusive. So there's this whole series put out by people in Washington on inclusive STEM. [...] They talk a lot about how storytelling can bring in non-Western cultures in different ways and make the activity more personal to them if you ask the kids first what they know about it through storytelling. [...] I do bring in different cultural activities, Celtic knots, different African math games. So I do make an effort in the activities to bring activities from different cultures, but also input inclusive ideas in there.

This example of Taylor choosing to include a variety of activities that draw upon different cultures, ways of knowing, and traditions was coded as external recognition of people of color as physicists and interest due to their effort to provide activities (material resource) related to science that might also be of interest to a wide range of participants. They are again recognizing people of color as scientists and are emphasizing different ways of knowing and interacting with physics in order to create a third space that provides participants with recognition. This effort is directly related to counter-storytelling and highlighting voices of color because Taylor is purposefully trying to uplift "non-Western" ideals and cultures within these activities.

Funding: Finally, Taylor discusses some challenges that they faced during this summer camp, and their other outreach work, related to funding the program. When thinking about funding intended to be used for increasing diversity through outreach, Taylor had a critical perspective on institutional systems that may inhibit this work.

I think the funding sources and the short funding cycle of NSF has a large impact on how we can affect diversity through outreach. [...] They give you a three-year grant, and they want to know how you're going to affect diversity with your outreach in three years. And I say, 'You can't,' because you have to make the interventions before high school. And you're not going to know if they're effective until well after college.

This segment of the interview highlights a challenge that Taylor faces when trying to secure the material resource of funding in order to create a sustainable summer program. We believe that this challenge is an example of interest convergence within the funding system in the United States as the National Science Foundation places structural limits on its funding models that may be in direct conflict with goals of advancing the needs of people from underrepresented groups. Furthermore, this notion of change within short amounts of time is a white-centered view point and intrinsically beneficial to white researchers as opposed to researchers of color and minority populations.

\section{IMPLICATIONS AND CONCLUSIONS}

Overall, Taylor's interview provided insight into the challenges and choices that were made for an informal physics program that is striving toward equity and inclusivity through the use of a third space. In this paper, we have demonstrated with a concrete example that by using both the CRT and CPI frameworks, we can understand ways in which informal programs are providing support (or are struggling to do so) to those with marginalized voices. We extended CRT and CPI beyond formal, classroom environments, in order to gain new perspectives within informal physics spaces. Both CRT and CPI can become an essential theoretical framework for analysis within informal physics education research and can be used to develop future informal programs. In future work we plan to analyze more informal physics programs, including those that have less design elements for equity and inclusion. Using CRT and CPI in this way, we will be able to identify elements that are important for practitioners who are striving to create inclusive informal spaces, and hopefully provide tools to improve informal physics spaces.

\section{ACKNOWLEDGMENTS}

We thank Dena Izadi for help with the interview, Simone Hyater-Adams for support with using the CPI framework, and Dr. Carter Andrews for teaching the 2019 CRT course. 
[1] Hazari, Z., et. al. "Connecting high school physics experiences, outcome experiences, physics identity, and physics career choice: A gender study." Journal of Research in Science Teaching. Vol 47, Issue 8. Feb. 2010.

[2] National Research Council. Learning Science in Informal Environments: People, Places, and Pursuits. 2009.

[3] Marie, A. and Ivie, R. "Women in Physics and Astronomy, 2019." American Institute of Physics. March 2019.

[4] R. Czujko, R. Ivie, and J. H. Stith, "Untapped talent: The African American presence in Physics and the Geosciences", AIP Report. Number R-44. (Statistical Research Center of the American Institute of Physics, College Park, MD, 2008).

[5] L. Merner, "African American participation among Bachelors in the Physical Sciences and Engineering", AIP Focus On (AIP, College Park, MD, 2015)

[6] Rolin, K.,"Gender and physics: Feminist philosophy and science education." Science Education. Nov. 2008, Vol. 17, Num. 10, Pgs 1111-1125.

[7] Gaskell, J. "Engaging Science Education Within Diverse Cultures." Curriculum Inquiry, Jan. 2015. Pgs 235-249.

[8] Gonsalves, A. "Persistent discourse in physics education: gender neutrality and the gendering of competence." Cultural Studies of Science Education June 2014. Vol. 9, Issue 2. Pgs 461-467.

[9] Hayter-Adams, S., et. al. "Critical look at physics identity: An operationalized framework for examining race and physics identity." Physical Review Physics Education Research. Vol 14. 2018.

[10] Moje, E. et. al. "Working toward third space in content area literacy: An examination of everyday funds of knowledge and Discourse." Reading Research Quarterly. Vol. 39, No. 1. 2004.

[11] Soja, E. Thirdspace: Journeys to Los Angeles and other realand-imagined places. Blackwell Publishers, Massachusetts. 1996.

[12] Gutiérrez, K. D., Baquedano-López, P., Tejeda, C., and Rivera, A. "Hybridity as a tool for understanding literacy learning: Building on a syncretic approach". Paper presented at American Educational Research Association, Montreal, Quebec, Canada. April, 1999.

[13] Calabrese Barton, A., et. al. " Creating Hybrid Spaces for Engaging School Science Among Urban Middle School Girls." American Education Research Journal. March 2008, Vol. 45, No. 1, pp. 68-103. 2007.

[14] Albright, A., Choreographing difference: The body and identity in contemporary dance. Wesleyan University, 2010.

[15] Delgado, R., Stefancic, J. Critical race theory: An introduction. New York, NY: NYU Press. 2012.

[16] Rosa, K. and F. M. Mensah. "Educational pathways of Black women physicists: Stories of experience and overcoming obstacles in life." Physics Review Physics Education Research. Vol 12. 2016

[17] Parsons, E. "Unpacking and Critically Synthesizing the Literature on Race and Ethnicity in Science Education." Handbook of Research on Science Education. Vol. 2. 2014. Pg 167-185.

[18] Hayter-Adams, S., et. al. (in press). "(De)Constructing Black Physics Identity: linking individual and social constructs using the Critical Physics Identity Framework." Physical Review Physics Education Research.
[19] Carlone, H. and A. Johnson. "Understanding the science experiences of successful women of color: Science identity as an analytic lens." Journal of Research in Science Teaching. Vol 47, Issues 8. 2007.

[20] Nasir. N. Racialized Identities: Race and achievement among African American Youth. Stanford University Press, Stanford, California. 2012.

[21] Williams, T. "The intersection of identity and performing arts of Black phycists." Thesis submitted to the Department of Physics at Mt. Holyoke College. 2018.

[22] Lynn, M. "Forward: Moving critical race theory in education from a problem-posing mindset to a problem-solving mindset." In DeCuir-Gunby, J., et. al. Understanding Critical Race Research Methods and Methodologies: Lessons from the Field. New York, NY: Routledge. 2019. 